CVIA

REVIEW ARTICLE

pISSN 2508-707X / elSSN 2508-7088 https://doi.org/10.22468/cvia.2018.00122 CVIA 2018;2(4):176-186

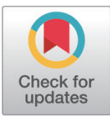

\section{Ischemic Heart Disease and Heart Failure: Advanced Magnetic Resonance Spectroscopy and Metabolic Imaging}

\author{
Gwang-Won Kim', Yun-Hyeon Kim², Gwang-Woo Jeong ${ }^{2}$ \\ 'Advanced Institute of Aging Science, Chonnam National University, Gwangju, Korea \\ ${ }^{2}$ Chonnam National University Hospital \& Medical School, Gwangju, Korea
}

\begin{abstract}
Ischemic heart disease and heart failure are common cardiac disorders. Magnetic resonance spectroscopy (MRS) is a non-invasive diagnostic tool for biochemical characterization of normal and abnormal tissues in the heart that has advantages over other diagnostic methods for quantification of myocardial metabolism without the use of contrast agents or invasive radiation. ${ }^{1} \mathrm{H}$ MRS and ${ }^{31} \mathrm{P}$ MRS are mainly used in clinical and preclinical research to monitor metabolic changes in the myocardium, providing valuable information on metabolite-based diagnostic and therapeutic outcomes. This review discusses the potential diagnostic biomarkers for ischemic heart disease and heart failure in multinuclear MRS and metabolic imaging. In addition, the future directions of MRS including hyperpolarized ${ }^{13} \mathrm{C}$ MRS and highfield-strength MRS techniques, which are useful for early diagnosis and prediction of therapeutic response in heart diseases, are briefly reviewed.
\end{abstract}

Key words Heart - Heart failure - Ischemic heart disease

Magnetic resonance spectroscopy · Metabolism.
Received: May 18, 2018

Accepted: September 10, 2018

Corresponding author

Yun-Hyeon Kim, MD, PhD

Chonnam National University Hospital \&

Medical School, 42 Jebong-ro, Dong-gu,

Gwangju 61469, Korea

Tel: 82-62-220-5747

Fax: 82-62-226-4380

E-mail: yhkim001@jnu.ac.kr

\section{INTRODUCTION}

Cardiovascular disease refers to several conditions of the heart and blood vessels, including ischemic heart disease (coronary heart disease), heart failure, cerebrovascular disease, elevated blood pressure, peripheral artery disease, rheumatic heart disease, and congenital heart disease. Ischemic heart disease is the principal etiology of heart failure; in particular, myocardial ischemia plays an important role in cardiac remodeling, a process that leads to progressive change in the shape and size of the heart and significantly worsens the prognosis of patients with heart failure [1].

Ischemic heart disease and heart failure lead to left ventricular (LV) dysfunction including systolic and diastolic dysfunction, which have been shown to have poor prognosis with high mortality at the last stage, and sudden cardiac death [2]. Ischemic heart disease and heart failure are common cardiac disorders in the United States, accounting for up to $45.1 \%$ and $8.5 \%$

(c) This is an Open Access article distributed under the terms of the Creative Commons Attribution Non-Commercial License (https://creativecommons.org/licenses/bync/4.0) which permits unrestricted non-commercial use, distribution, and reproduction in any medium, provided the original work is properly cited. of all cardiac deaths in 2014, respectively [3]. Early diagnosis is essential to prevent the progression of these diseases.

The heart has a very high and continuous demand for energy production in the form of adenosine triphosphate (ATP) [4,5]. Under normoxic conditions, more than $95 \%$ of the ATP generated in the heart is derived from oxidative phosphorylation in the mitochondria. The remaining 5\% comes mainly from glycolysis and to a lesser extent from the Krebs cycle [6]. Fatty acids enter the mitochondria, where $\beta$-oxidation takes place, after which the intermediate acetyl-coenzyme A enters the Krebs cycle [7]. Glucose is converted to pyruvate in the cytoplasm by glycolysis, and then the pyruvate enters the Krebs cycle in the mitochondria [7]. In addition, ATP is synthesized in the mitochondria and reacts with creatine $(\mathrm{Cr})$ in the creatine kinase $(\mathrm{CK})$ reaction to form phosphocreatine $(\mathrm{PCr})$ as follows [8]: ATP+ $\mathrm{Cr} \leftrightarrow \mathrm{ADP}+\mathrm{PCr}+\mathrm{H}^{+}$.

Coronary angiography is recognized as the gold standard for diagnosis of ischemic heart disease, whereas echocardiography is the gold standard for assessment of LV systolic dysfunction and detection of systolic heart failure $[9,10]$. MRI is a noninvasive modality that has been used to assess cardiac morphology, 
function, perfusion, and viability. Moreover, echocardiography is the most useful noninvasive imaging modality in the diagnosis of heart failure. Unlike MRI and echocardiography, magnetic resonance spectroscopy (MRS) allows investigation of intracranial cellular metabolism in vivo. Under the assumption that metabolite changes in abnormal tissue precede morphological changes, the magnetic resonance spectra represent specific biochemical information about metabolic changes at the cellular level and can support the clinical diagnosis because they provide information on the biochemistry and physiology of the corresponding disease $[11,12]$. Thus, MRS has become a tool of interest for diagnostic and prognostic assessment of ischemic heart disease and heart failure.

In vivo MRS plays an important role in early diagnosis and evaluation of effective therapeutic intervention in myocardial muscles. ${ }^{1} \mathrm{H}$ and ${ }^{31} \mathrm{P}$ MRS have predominantly been used to distinguish between non-viable and viable myocardium and to diagnose heart failure [13-17]. Moreover, with the advent of the 7-tesla (T) MRI system, spectral resolutions are enhanced even further compared with the $1.5 \mathrm{~T}$ and $3 \mathrm{~T}$ systems, providing more accurate quantification of cardiac metabolites. Recently, hyperpolarized ${ }^{13} \mathrm{C}$ MRS and metabolic imaging have opened new possibilities for assessing diagnostic and therapeutic biomarkers of cellular metabolic changes in heart diseases in both clinical and preclinical research [18-22]. This brief review discusses potential diagnostic biomarkers for ischemic heart disease and heart failure and further introduces the future directions of MRS including hyperpolarized ${ }^{13} \mathrm{C}$ MRS and high-field-strength MRS techniques.

\section{CARDIAC MAGNETIC RESONANCE SPECTROSCOPY}

Metabolism is an essential process for maintaining living cells, which are the fundamental units of all living tissues. Cardiac MRS is a noninvasive technique for biochemical characterization of normal and abnormal tissues of the heart and has been used to assess myocardial metabolism using the signals from nuclei, such as ${ }^{1}$ hydrogen $\left({ }^{1} \mathrm{H}\right),{ }^{13}$ carbon $\left({ }^{13} \mathrm{C}\right),{ }^{23}$ sodium $\left({ }^{23} \mathrm{Na}\right)$, and ${ }^{31}$ phosphorus $\left({ }^{31} \mathrm{P}\right)$.

${ }^{1} \mathrm{H}$ MRS has been applied to the heart because of its major advantages of higher sensitivity and spatial resolution [23]. This technique can identify hypertrophy of a remodeled myocardium but does not discriminate between nonviable and viable tissue [24]. It is widely recognized that the important ${ }^{1} \mathrm{H}$ metabolites in the myocardium are lipids (triglycerides) and $\mathrm{Cr}$. Myocardial infarction is associated with increased myocardial lipid content and decreased myocardial $\mathrm{Cr}$ content. The chemical shifts of ${ }^{1} \mathrm{H}$ metabolites in ${ }^{1} \mathrm{H}$ MRS are typically observed in the range of 0.0 to $9.0 \mathrm{ppm}$, whereas those of ${ }^{31} \mathrm{P}$ metabolites in
${ }^{31} \mathrm{P}$ MRS are widely observed in the range of $40 \mathrm{ppm} .{ }^{31} \mathrm{P} \mathrm{MRS}$ allows detection of a wider range of cardiac metabolites compared with ${ }^{1} \mathrm{H}$ MRS but has lower sensitivity. ${ }^{31} \mathrm{P}$ metabolites are abundant in viable tissues and play an important role as high-energy compounds that are regulated in intracellular metabolism. ${ }^{31} \mathrm{P}$ MRS is widely used for noninvasive measurement of intracellular $\mathrm{pH}$ and $\mathrm{Mg}^{2+}$ levels by utilizing the changes in chemical shifts between $\mathrm{PCr}$ and inorganic phosphate $(\mathrm{Pi})$ and between $\alpha$-ATP and $\beta$-ATP [25]. Most ${ }^{31} \mathrm{P}$ MRS studies demonstrated that the PCr/ATP ratio is an index of the energetic state of the heart. PCr is an important short-term reserve energy source that maintains a high phosphorylation potential under conditions of increased energy demand, such as during exercise and ischemia [26]. ATP is the direct energy source for energy-consuming reactions in the cell, whereas PCr acts as an energy storage compound and as an energy transport molecule in the CK-PCr energy shuttle [27]. Especially, a decreased myocardial PCr/ATP ratio is linked to increased mortality in patients with heart failure [28].

Beyond ${ }^{1} \mathrm{H}$ and ${ }^{31} \mathrm{P},{ }^{13} \mathrm{C}$ MRS is a useful tool for evaluating the kinetics of metabolism. ${ }^{13} \mathrm{C}$ MRS is an important modality capable of evaluating the kinetics of cardiac metabolism. Its sensitivity is very low because of its low natural abundance, even with exogenously introduced isotopic enrichment [29]. Advances in ${ }^{13} \mathrm{C}$ hyperpolarization, such as dissolution dynamic nuclear polarization (DNP), enhance the spectral sensitivity more than 10000 times compared with conventional ${ }^{13} \mathrm{C}$ MRS [30-33]. This technique allows quantification of metabolic reactions such as Krebs cycle flux and various metabolic pathways [16]. ${ }^{13} \mathrm{C}$-labeled pyruvate is a commonly used substrate for obtaining important information on the biochemical pathway as it can be converted to $\left[1-{ }^{13} \mathrm{C}\right]$ lactate, $\left[1-{ }^{13} \mathrm{C}\right]$ alanine, and $\left[{ }^{13} \mathrm{C}\right]$ bicarbonate and has been proposed as a cardioprotective agent during ischemic conditions $[24,29,34]$. Therefore, ${ }^{13} \mathrm{C}$ holds great potential for studying multiple metabolic pathways such as glycolysis, the tricarboxylic acid cycle, or $\beta$-oxidation in the myocardium [35].

\section{ISCHEMIC HEART DISEASE}

Ischemic heart disease is characterized by reduced blood flow and oxygen to the cardiac muscles, leading to regional ischemia and infarction. The main clinical issue in the treatment of patients with ischemic heart disease is identification of viable myocardium and its discrimination from non-viable necrotic tissue [36]. MRS is a potential diagnostic tool for distinguishing between nonviable and viable myocardium and has advantages over other diagnostic tools in the ability to determine myocardial viability without the use of contrast agents or invasive radiation [16]. 
In general, ${ }^{31} \mathrm{P}$ MRS is mainly used in clinical fields to assess cardiac metabolism in ischemic heart disease. In patients with $70 \%$ or greater stenosis of the left anterior descending coronary artery, the PCr/ATP ratio decreased from $1.45 \pm 0.31$ at rest to $0.91 \pm 0.24$ during hand-grip exercise and increased to $1.27 \pm$ 0.38 after recovery [17]. After revascularization, the PCr/ATP ratio was stable during the repeated exercise. In another study [15], the PCr/ATP ratio decreased by $25 \%$ during hand-grip exercise in 7 of 35 women with chest pain and normal coronary angiograph, suggesting microvascular coronary artery disease as the cause of the chest pain and consistent with the occurrence of myocardial ischemia. Interestingly, a 3-year follow-up study [37] on the prognostic implications of abnormal PCr/ATP ratio was performed in women with chest pain and normal coronary angiography, with or without an abnormal PCr/ATP ratio, and a reference group with coronary artery disease. The results demonstrated that a decrease in PCr/ATP of $1 \%$ increased the risk of a cardiovascular event by $4 \%$ after adjusting for coronary artery disease and cardiac risk factors, suggesting that the ${ }^{31} \mathrm{P}$ MRS stress test is a strong predictor of future cardiovascular events.

Similar to ischemic tissue, the PCr/ATP ratio in the infarcted region of patients with aortic stenosis (pressure gradient $>60$ $\mathrm{mm} \mathrm{Hg}$ ) decreased compared with that in healthy controls [38]. After surgical valve replacement, the $\mathrm{PCr} / \mathrm{ATP}$ ratio in patients increased from $0.80 \pm 0.25$ to $1.28 \pm 0.22$, and changes in cardiac energy metabolism showed a trend toward normalization. In addition, ATP content is used in clinical fields to evaluate myocardial viability. A human study by Yabe et al. [39] demonstrated that PCr and ATP contents decreased significantly in patients with both reversible and fixed ${ }^{201} \mathrm{Tl}$ defects, whereas ATP content only decreased in patients with fixed thallium defects. In nonviable infarcted canine myocardium, the PCr/ATP ratio, $\mathrm{PCr}$, and ATP were significantly decreased, and these alterations were confirmed using biopsy measurements [14]. In isolated rat hearts after 10-min coronary artery occlusion and 15-min reperfusion, the PCr level rapidly decreased at the onset of ischemia and rapidly recovered to the preischemic level after reperfusion (Fig. 1) [40]. However, in rat hearts, the PCr/ATP ratio could not be used to assess myocardial viability because $\mathrm{PCr}$ and ATP signals cannot be detected in the infarcted region [41].

In a human study using ${ }^{1} \mathrm{H}$ MRS, Bottomley and Weiss [13] demonstrated that $\mathrm{Cr}$ content was significantly lower in infarcted myocardium compared with viable myocardium. Patients with hypokinetic wall motion and those with akinetic or dyskinetic wall motion showed decreased $\mathrm{Cr}$ peaks compared with patients with normokinetic $\mathrm{LV}$ wall motion and normal controls (Fig. 2) [42]. Numerous ${ }^{1} \mathrm{H}$ MRS studies [14,43-45] were performed in animals to distinguish between nonviable

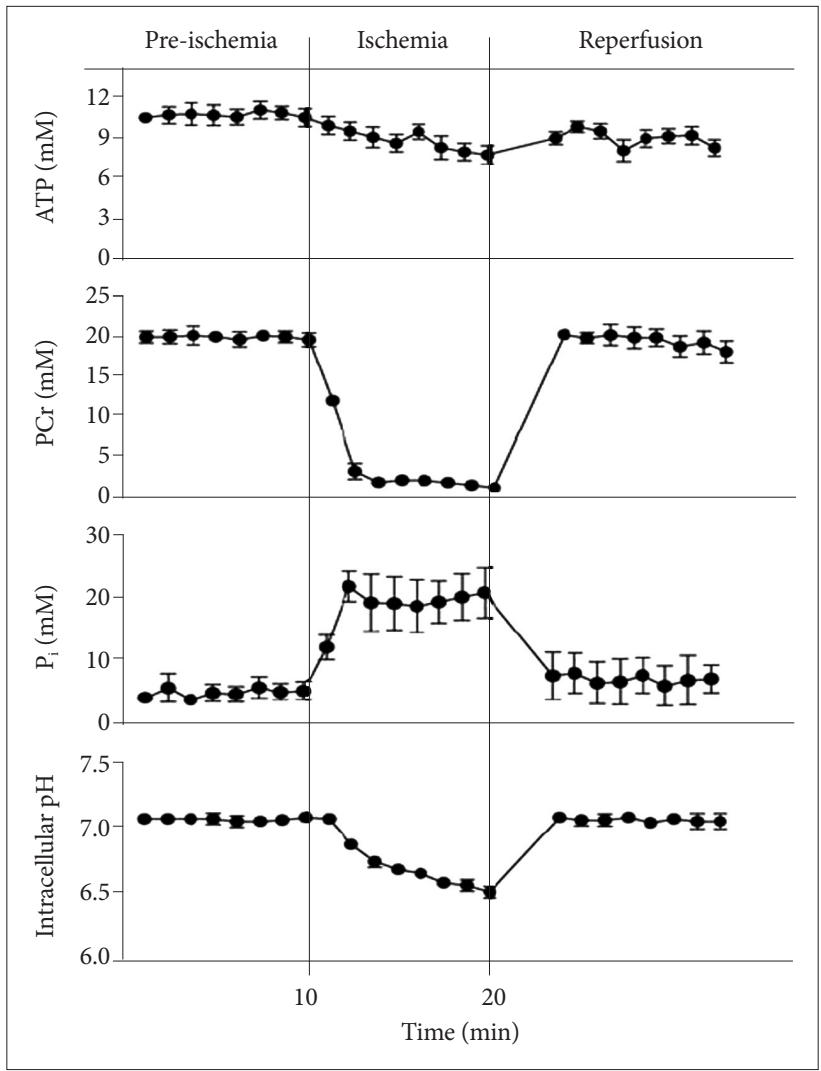

Fig. 1. Time-course changes in ATP, $\mathrm{PCr}, \mathrm{Pi}$, and $\mathrm{pH}$ before, during, and after ischemia in isolated rat hearts following 10-min coronary artery occlusion and 15-min reperfusion. The ATP level gradually decreased during ischemia and partially recovered to the pre-ischemic level after reperfusion. The PCr level rapidly decreased at the onset of ischemia and rapidly recovered to pre-ischemic level after reperfusion. The $\mathrm{Pi}$ level rapidly increased at the onset of ischemia and rapidly decreased to the pre-ischemic level after reperfusion. The $\mathrm{pH}$ level gradually decreased during ischemia and rapidly recovered to the pre-ischemic level after reperfusion. Reprinted from Schroeder et al. Cardiovasc Res 2010;86:82-91, with permission of Oxford University Press [40]. ATP: adenosine triphosphate, PCr: phosphocreatine, $\mathrm{Pi}$ : inorganic phosphate.

and viable myocardium. The $\mathrm{Cr}$ content in nonviable infarcted canine myocardium was decreased compared with that in viable myocardium [14]. Myocardial infarction is related to accumulation of lipids. Evanochko et al. [44] investigated lipid content changes in the canine myocardium after 24-h coronary occlusion and reported increased lipid content in myocardia with moderate blood flow reduction (flow $5-50 \%$ of control) compared with myocardia with normal blood flow or severe blood flow reduction (flow $<5 \%$ of control). In a swine model after 48-min coronary artery occlusion and 2-h reperfusion, the Cr level decreased from $18.28 \pm 0.84 \mu \mathrm{mol} / \mathrm{g}$ fresh weight in controls to $12.58 \pm 2.89 \mu \mathrm{mol} / \mathrm{g}$ fresh weight $(\mathrm{p}<0.05)$ and $9.96 \pm 2.21$ $\mu \mathrm{mol} / \mathrm{g}$ fresh weight $(\mathrm{p}<0.01)$ in at-risk and necrotic areas, respectively (Fig. 3) [45]. In addition, high-resolution magic angle spectroscopy spectra showed an increase in lipid signals at 0.9 ppm and 1.28 ppm as markers of necrotic tissue. In a similar 

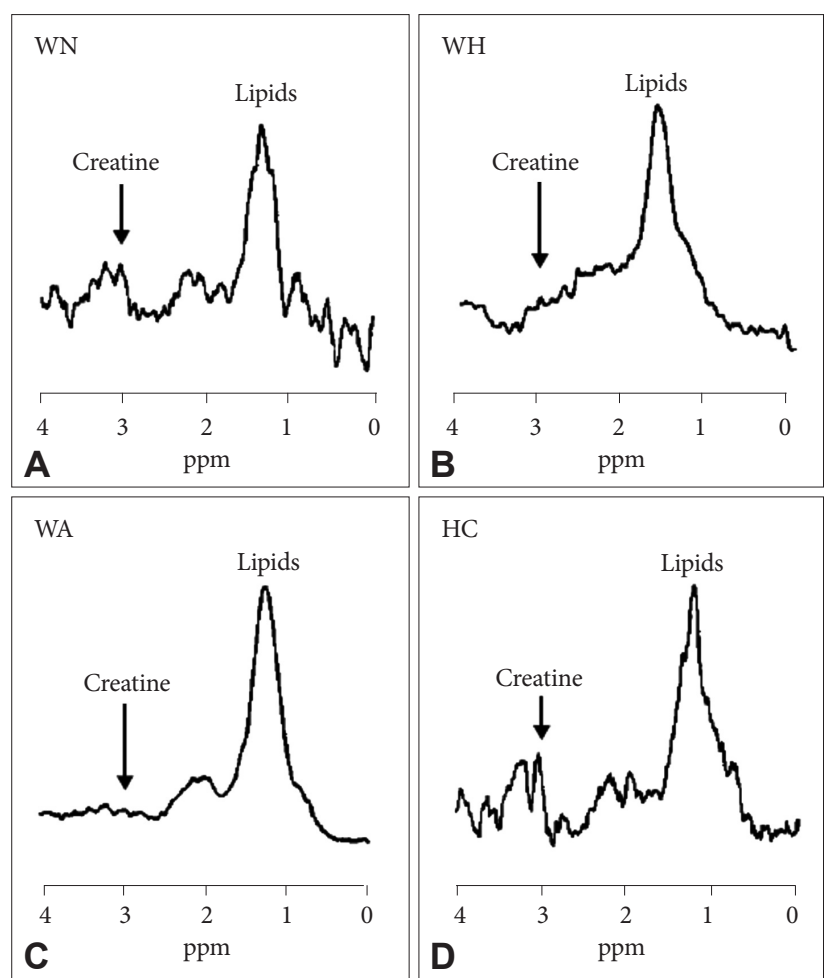

Fig. 2. Myocardial ${ }^{1} \mathrm{H}$ MR spectra obtained in the left ventricular (LV) wall of patients with ischemic heart disease (A-C) and a healthy control (D). Patients in hypokinetic wall motion (WH) and akinetic or dyskinetic wall motion (WA) showed decreased creatine peaks compared with patients in normokinetic LV wall motion (WN) and healthy controls (HC). Reprinted from Nakae et al. J Cardiovasc Magn Reson 2004;6:685-696 [42].

study [43], lipid content increased in the regions corresponding to myocardial infarction, particularly in the periphery of the infarction. ${ }^{1} \mathrm{H}$ MRS is a valuable diagnostic tool capable of differentiating normal, at-risk, and infarcted myocardium.

During the last two decades, ${ }^{13} \mathrm{C}$ and ${ }^{23} \mathrm{Na}$ MRS have been performed to identify myocardial viability in animals, but not in humans. Horn et al. [46] demonstrated that sodium $\left({ }^{23} \mathrm{Na}\right)$ content was increased in non-viable myocardium of rats. Hyperpolarized ${ }^{13} \mathrm{C}$ MRS is used in the preclinical field to assess cardiac metabolism in viable and non-viable myocardium $[18,19,47]$. Golman et al. [19] investigated myocardial viability in a pig model of ischemia-reperfusion using hyperpolarized ${ }^{13} \mathrm{C}$ MRS and metabolic imaging and reported a decreased level of $\left[{ }^{13} \mathrm{C}\right]$ bicarbonate in stunned viable myocardium after $15-$ min coronary occlusion (ischemic) and decreased levels of $\left[{ }^{13} \mathrm{C}\right]$ bicarbonate and $\left[1-{ }^{13} \mathrm{C}\right]$ alanine in non-viable myocardium after 45-min occlusion (infarction) (Fig. 4). In a similar study [47], at reperfusion after 15-min of coronary occlusion, the $\left[1-{ }^{13} \mathrm{C}\right]$ lactate/ $\left[{ }^{13} \mathrm{C}\right]$ bicarbonate ratio was increased in the myocardial area in at-risk rats (Fig. 5). The Krebs cycle plays a fundamental role in cardiac energy production. A hyperpolarized ${ }^{13} \mathrm{C}$ MRS study [20] using $\left[2-{ }^{13} \mathrm{C}\right]$ pyruvate measured Krebs

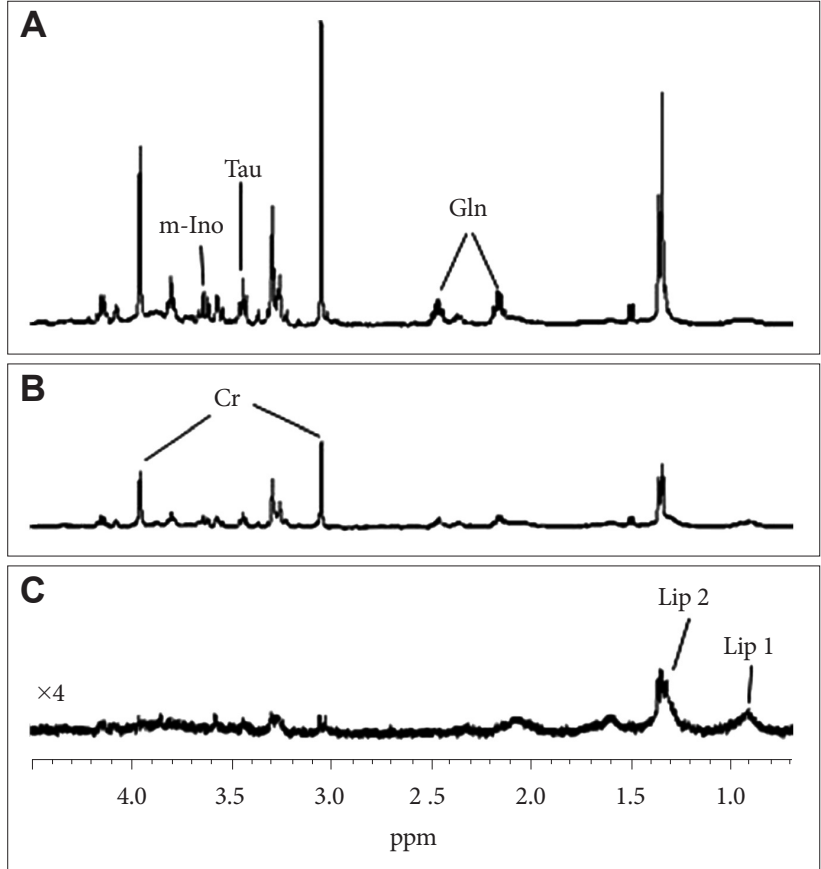

Fig. 3. ${ }^{1} \mathrm{H}$ HR-MAS spectra of control (A), at-risk (B), and necrotic (C) tissue after myocardial infarction in a swine model following 48min coronary artery occlusion and 2-h reperfusion. Creatine concentration in at-risk (B) and necrotic (C) tissue decreased. Spectra $A$ and $B$ are scaled for a similar tissue mass, and spectrum $(C)$ has a vertical scale with 4-fold enlargement. Reprinted from Barba et al. MAGMA 2007;20:265-271, with permission of Springer Nature [45]. Lip 1: $\mathrm{CH}_{3}$ of lipid chains, Lip 2: $-\mathrm{CH}_{2}$ - of lipid chains, Cr: creatine, GIn: glutamine, Tau: taurine, m-Ino: myo-inositol.

cycle flux in real time in perfused rat hearts. The data suggested that the levels of $\left[1{ }^{13} \mathrm{C}\right]$ citrate and $\left[5{ }^{13} \mathrm{C}\right]$ glutamate were decreased after 10-min of global ischemia in an isolated heart, whereas that of lactate was increased. Hyperpolarized ${ }^{13} \mathrm{C}$ MRS allows determination of myocardial viability by evaluating the severity of hypokinetic wall motion.

Major multinuclear MRS techniques including ${ }^{1} \mathrm{H},{ }^{31} \mathrm{P}$, hyperpolarized ${ }^{13} \mathrm{C}$, and ${ }^{23} \mathrm{Na}$ MRS have the potential to discriminate the viability of ischemic myocardium in preclinical and/or clinical studies. ${ }^{1} \mathrm{H}$ MRS is ideally suited to assess the metabolism of the infarcted tissue through increased lipid and decreased $\mathrm{Cr}$. The PCr/ATP ratio in cardiac energy metabolism is a potentially important diagnostic biomarker for quantifying cardiac function, especially in ischemic heart disease. Also, hyperpolarized ${ }^{13} \mathrm{C}$ MRS studies $[19,47]$ suggested that an increased ratio of $\left[1-{ }^{13} \mathrm{C}\right]$ lactate/ $\left[{ }^{13} \mathrm{C}\right]$ bicarbonate or decreased signals of both $\left[{ }^{13} \mathrm{C}\right]$ bicarbonate and $\left[1-{ }^{13} \mathrm{C}\right]$ alanine predict myocardial infarction. In addition, increased ${ }^{23} \mathrm{Na}$ content could be an indicator of myocardial infarction.

\section{HEART FAILURE}

Heart failure is a common final pathway of various cardio- 


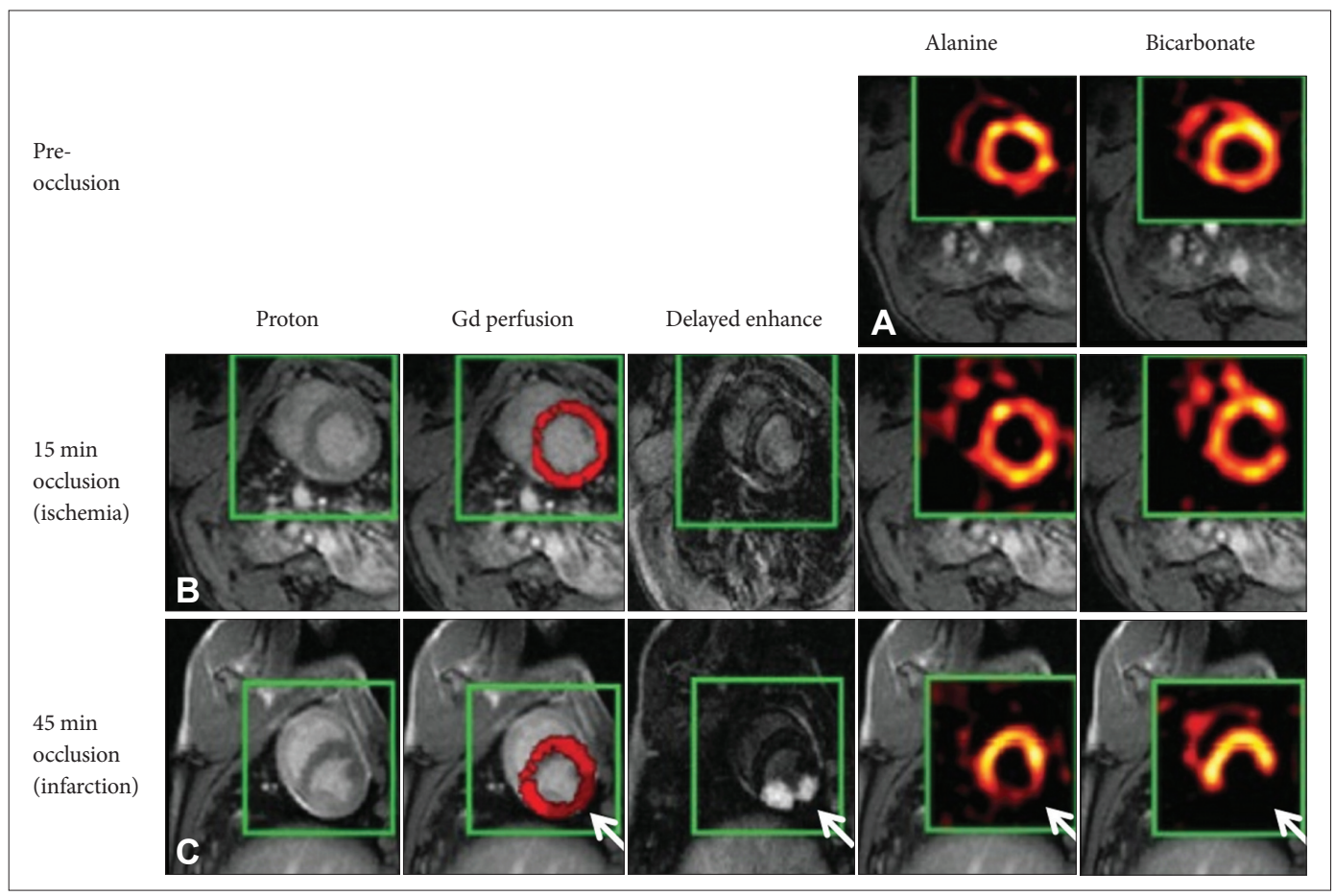

Fig. 4. Proton MR images with semiquantitative $\mathrm{Gd}$-perfusion and delayed enhancement and metabolic images of $\left[1-{ }^{13} \mathrm{C}\right]$ alanine and $\left[{ }^{13} \mathrm{C}\right]$ bicarbonate before $(A)$ and after $(B, C)$ occlusion in a pig model. Decreased level of bicarbonate in stunned viable myocardium after 15-min coronary occlusion (B) and decreased levels of bicarbonate and alanine in non-viable myocardium (arrows) after 45-min occlusion (C). Reprinted from Golman et al. Magn Reson Med 2008;59:1005-1013, with permission of John Wiley and Sons [19].

vascular diseases [48]. The most common causes of heart failure are dilated cardiomyopathy (DCM), hypertrophic cardiomyopathy $(\mathrm{HCM})$, and cardiomyopathy related to metabolic syndrome [7]. DCM is characterized by LV systolic dysfunction with associated increase in mass and volume. HCM is a myocardial disease defined by unexplained LV hypertrophy, usually asymmetrical and involving the interventricular septum [49]. Alterations in cardiac energy metabolism play an important role in the mechanisms of heart failure [50]. Myocardial lipid overstorage leads to cardiomyopathy; however, advanced heart failure causes lipolysis via sympathetic nerve activation [51].

Patients with heart failure with preserved ejection fraction (HFpEF) show decreased PCr/ATP ratio by ${ }^{31} \mathrm{P}$ MRS compared with healthy controls. The PCr/ATP ratio in patients with heart failure treated with trimetazidine increased by $33 \%$ from $1.35 \pm$ 0.33 to $1.80 \pm 0.50$, resulting in decreased New York Heart Association (NYHA) class and increased ejection fraction [52]. Such evidence suggests that the decreased PCr/ATP ratio was attributable to the pathophysiology of heart failure. Studies [53-55] on higher-energy metabolism using ${ }^{31} \mathrm{P}$ MRS in patients with DCM reported decreased PCr/ATP ratios (Fig. 6). This decrease correlates with the clinical severity of heart failure estimated from the NYHA class [53] and LV ejection fraction [54,55]. Interestingly, the PCr/ATP ratio after drug treatment increased by $42 \%$, from $1.51 \pm 0.32$ to $2.15 \pm 0.27$ [53]. However, in patients with
DCM, a ${ }^{31}$ P MRS study [27] with spatial localization and optimum point-spread function, a new method for absolute quantification of myocardial high-energy phosphate level, reported $51 \%$ and 35\% reductions in PCr and ATP levels, respectively, resulting in a $25 \%$ decrease in $\mathrm{PCr} / \mathrm{ATP}$ ratio. These results suggest that the PCr/ATP ratio underestimates the true extent of energetic imbalance.

Cardiac ${ }^{31} \mathrm{P}$ MRS has also been used to evaluate disordered energy metabolism and $\mathrm{pH}$ value in hypertrophic myocardium [26,55-57]. Patients with HCM showed a decreased PCr/ATP ratio compared with healthy controls (Fig. 7); however, the PCr/ ATP ratio was not correlated with degree of LV hypertrophy [57]. In addition, patients with nonobstructive HCM showed a significant increase in myocardial lipids and a decrease in $\mathrm{PCr} /$ $\gamma$-ATP ratio compared with competitive athletes [58]. During myocardial ischemia, oxygen consumption and ATP production are reduced, causing accelerated glycolysis and lactate production; in this situation, $\mathrm{pH}$ decreases and cell function is impaired [59]. One study [55] reported that the myocardial $\mathrm{pH}$ level (7.07 \pm 0.07$)$ in patients with HCM was lower than that in healthy controls (7.15 \pm 0.03$)$. Patients with type I or type II diabetes showed a decreased PCr/ATP ratio compared with healthy controls [60,61], and the PCr/ATP ratio correlated negatively with fasting plasma free fatty acid concentration [60].

${ }^{1} \mathrm{H}$ MRS studies [51,62,63] have demonstrated that lipid is 


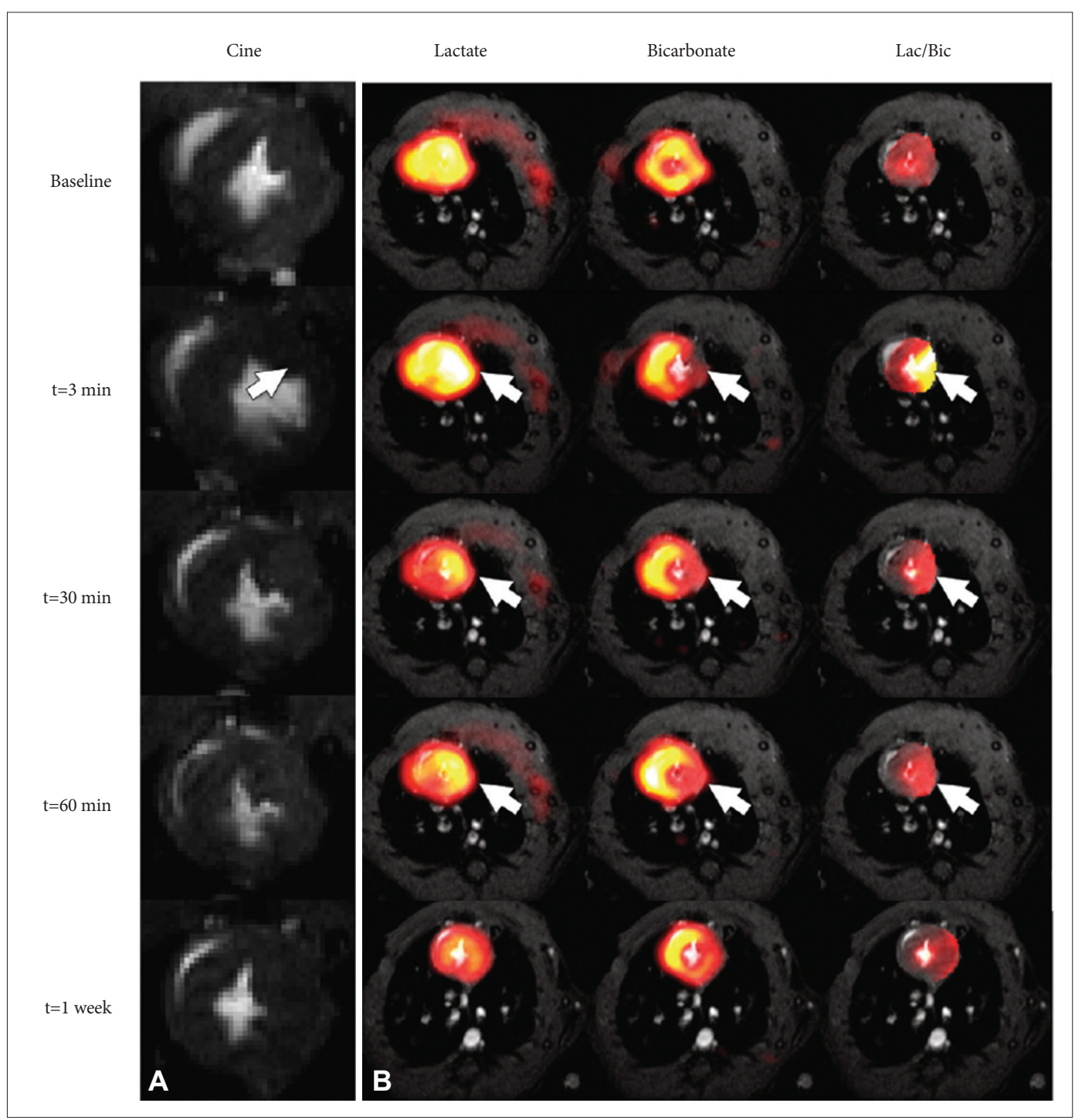

Fig. 5. Example images at the five time points in a rat. (A) Cine images at reperfusion in a rat model show reduced systolic wall thickening in the myocardial area at risk (AAR), which is the myocardial territory distal to the coronary occlusion (anterior and lateral walls) (arrow). (B) Metabolic maps of $\left[1-{ }^{13} \mathrm{C}\right]$ lactate, $\left[{ }^{13} \mathrm{C}\right]$ bicarbonate, and $\left[1-{ }^{13} \mathrm{C}\right]$ lactate $/\left[{ }^{13} \mathrm{C}\right]$ bicarbonate $(\mathrm{Lac} / \mathrm{Bic})$ ratio. In the AAR, the Lac/Bic ratio is increased. Hyperpolarized $\left[1{ }^{13} \mathrm{C}\right]$ pyruvate was injected at the following times in the course of reperfusion: $3 \mathrm{~min}, 30 \mathrm{~min}, 60 \mathrm{~min}$, and 1 week after 15-min coronary occlusion. Reprinted from Oh-lci et al. Radiology 2016;278:742-751, with permission of Radiological Society of North America [47].

more strongly associated with the specific cause of disease than the severity of cardiac dysfunction, and that $\mathrm{Cr}$ reflects the severity of heart failure. Nakae et al. [51] reported that lipid content was significantly lower in patients with HCM than in healthy controls; however, the lack of a significant difference in lipid between patients with DCM and healthy controls suggests that lipid may be related to an overweight state. The $\mathrm{Cr}$ level in patients with chronic heart failure (LV ejection fraction $<45 \%$ ) was significantly lower than that in healthy controls [62]. Two studies $[51,63]$ demonstrated that patients with HCM and DCM showed decreased $\mathrm{Cr}$ content, which correlated positively with LV ejection fraction. Myocardial energy expenditure is associated with changes in LV ejection fraction. Du et al. [64] revealed that se- rum metabolomic markers such as 3-hydroxybutyrate, acetone, and succinate were significantly increased in patients with heart failure, and that these changes could be used as potential indicators of heart failure. Myocardial triglyceride content is significantly higher in patients with type II diabetes compared with healthy volunteers [65]. Obesity is also associated with increased myocardial lipidosis [66].

Schroeder et al. [67] investigated the cellular metabolite change in the myocardium of a porcine model using hyperpolarized ${ }^{13} \mathrm{C}$ MRS and suggested that the ratios of $\left[5{ }^{-13} \mathrm{C}\right]$ glutamate/[1$\left.{ }^{13} \mathrm{C}\right]$ pyruvate and $\left[{ }^{13} \mathrm{C}\right]$ bicarbonate/ $\left[1-{ }^{13} \mathrm{C}\right]$ pyruvate significantly decreased with progression of DCM. In hypertrophied hearts, the rate of conversion of pyruvate to lactate is increased 


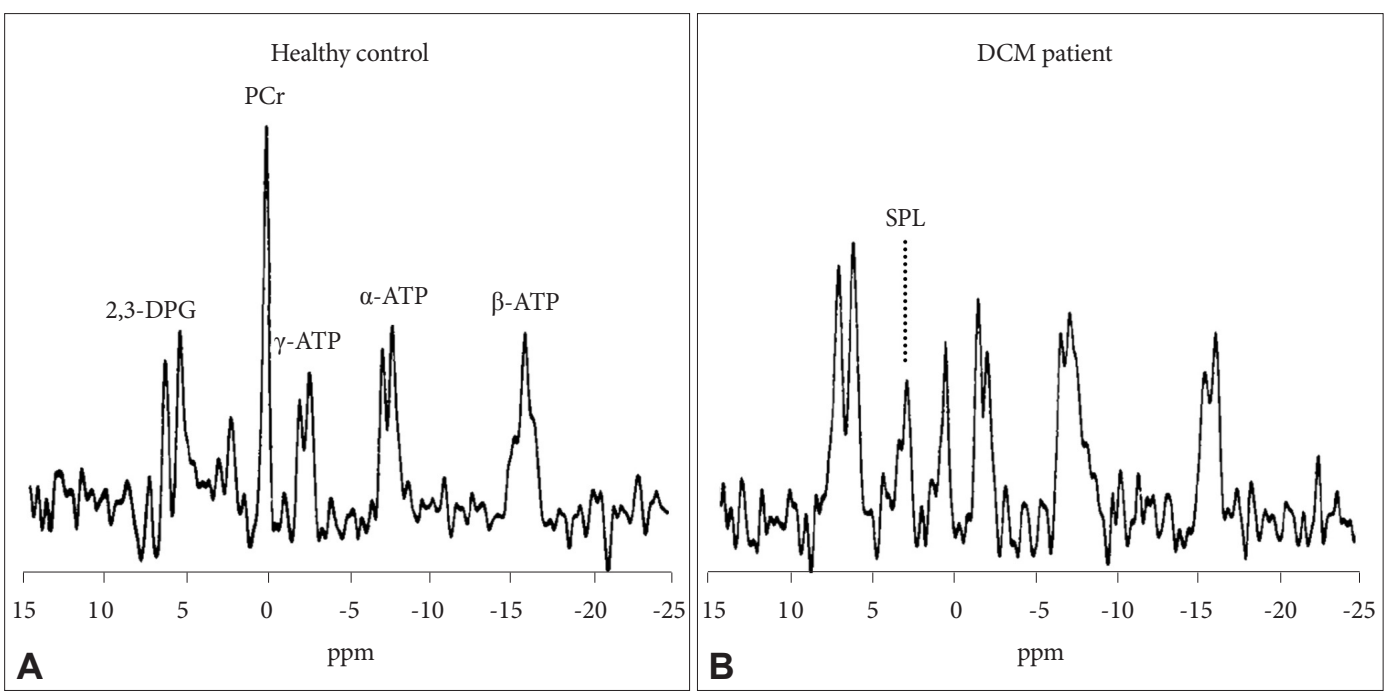

Fig. 6. Myocardial ${ }^{31} \mathrm{P}$ MR spectra from a healthy control $(A)$ and a patient with dilated cardiomyopathy (B). The PCr/ATP ratio in a patient with DCM was significantly lower compared with a healthy control. Reprinted from de Roos et al. J Magn Reson Imaging 1992;2:711-719, with permission of John Wiley and Sons [55]. 2,3-DPG: 2,3-diphosphoglycerate, PCr: phosphocreatine, ATP: adenosine triphosphate, DCM: dilated cardiomyopathy, SPL: serum phospholipids.

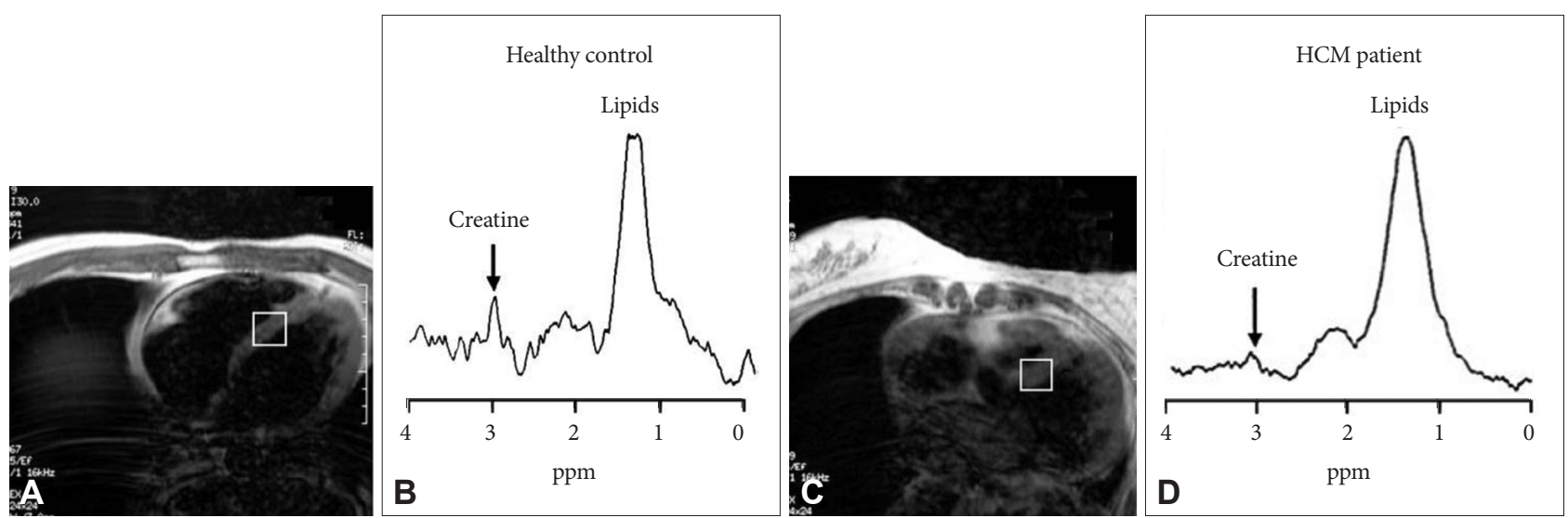

Fig. 7. Spin-echo MR images (A and C) and ${ }^{1} \mathrm{H}$ MR spectra from a 66-year-old healthy control (B) and a 79-year-old patient with hypertrophic cardiomyopathy $(\mathrm{HCM})(\mathrm{D})$. The creatine concentrations in the healthy control and patient were 25.0 and $15.6 \mu \mathrm{mol} / \mathrm{g}$ wet weight, respectively. Reprinted from Nakae et al. J Am Coll Cardiol 2003;42:1587-1593, with permission of Elsevier Science and Technology Journals [63].

[68]. Further studies using hyperpolarized ${ }^{13} \mathrm{C}$ metabolic imaging would be useful to assess diagnosis and therapeutic evaluation in heart failure, providing more accurate metabolic mapping.

Although both PCr and ATP contents decrease in heart failure, the PCr/ATP ratio correlates with clinical severity of heart failure. ${ }^{1} \mathrm{H}$ MRS has demonstrated decreased lipid content in HCM and decreased lipid and Cr contents in both HCM and DCM. These cardiac metabolites could be reliable predictors of heart failure. Very few clinical MRS studies have focused on heart failure; thus, future studies combining ${ }^{1} \mathrm{H},{ }^{13} \mathrm{C}$, and ${ }^{31} \mathrm{P}$ MRS techniques are needed.

\section{FUTURE DIRECTIONS}

Today, the most frequently used magnetic resonance scan- ners for cardiac MRS operate at $1.5 \mathrm{~T}$ and $3 \mathrm{~T}$. However, clinical application of ${ }^{1} \mathrm{H}$ and ${ }^{31} \mathrm{P}$ MRS is limited by the many unresolved problems related to heavy spectral overlap. The application of a higher magnetic field is a good solution to reduce the limitations of in vivo cardiac MRS studies. A higher field strength provides accurate and reliable interpretation of the magnetic resonance spectra. For example, the spectral signal-to-noise ratio at $3 \mathrm{~T}$ is about two times higher than that at $1.5 \mathrm{~T}$ [69]. With an increase in magnetic field strength, the signal-to-noise ratio and temporal resolution also increase. However, higher field strengths are also associated with magnetic field inhomogeneities, motion-induced artifacts, increased chemical shift displacement errors, and higher specific absorption rate. Some of these issues are inherent physical properties of the biochemical component under investigation, whereas others may be addressed by improving the technology, either in pulse sequence design or 

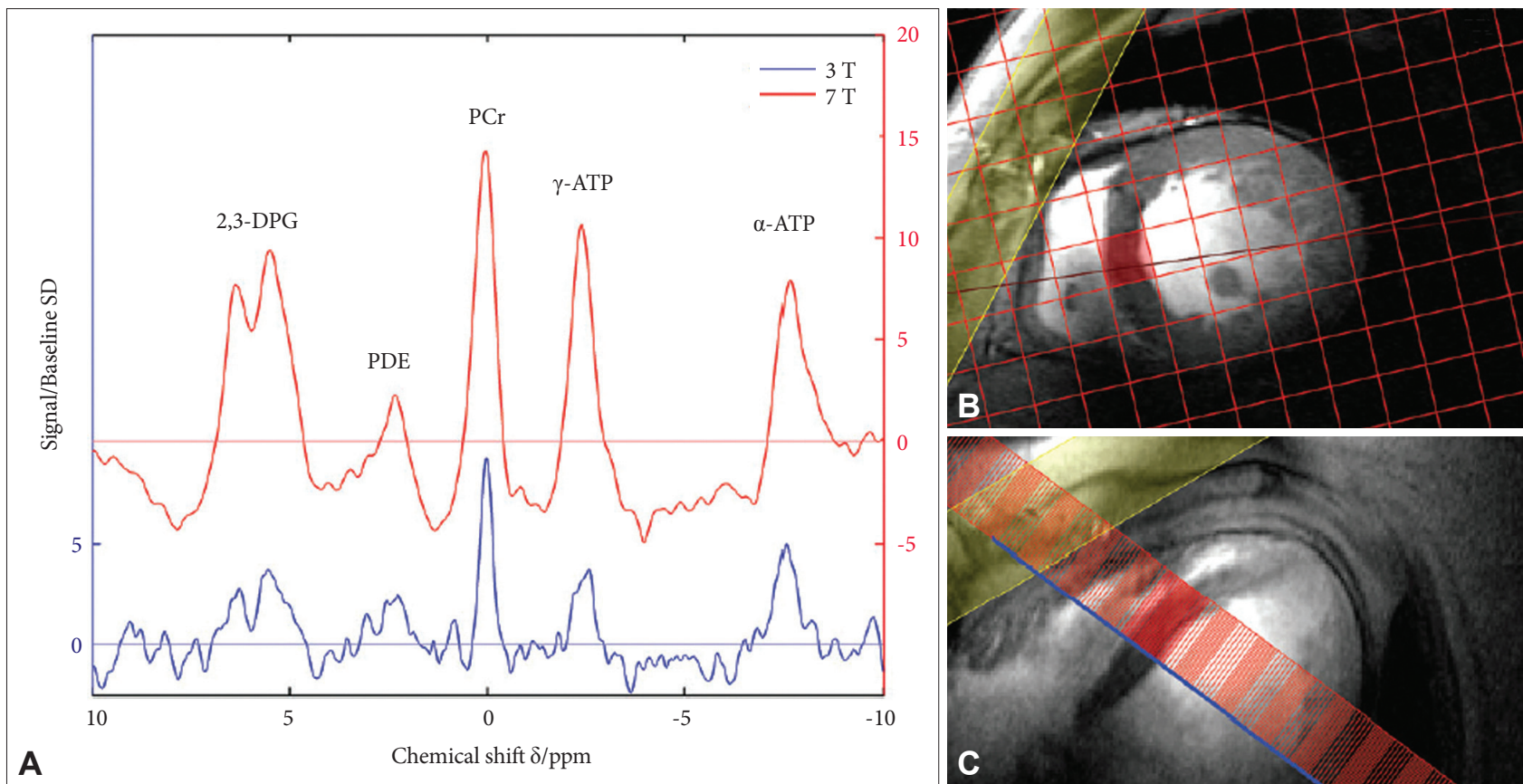

Fig. 8. Comparison of MR spectra in a 57-year-old woman with dilated cardiomyopathy (DCM) at $3 \mathrm{~T}$ and $7 \mathrm{~T}$ (A). The increase in SNR at $7 \mathrm{~T}$ is readily apparent. Corresponding mid-short axis view (B) and four-chamber view (C) were acquired at 7 T. The spectroscopy matrices are overlaid in the red voxels plotted in $B$ and $C$ is highlighted. The yellow-shaded region denotes the regional saturation slab used to suppress signal from overlying skeletal muscle. Reprinted from Valkovič et al. Magn Reson Med 2017;78:1667-1673, with permission of Radiological Society of North America [73]. 2,3-DPG: 2,3-diphosphoglycerate, PDE: phosphodiesters, PCr: phosphocreatine, ATP: adenosine triphosphate.
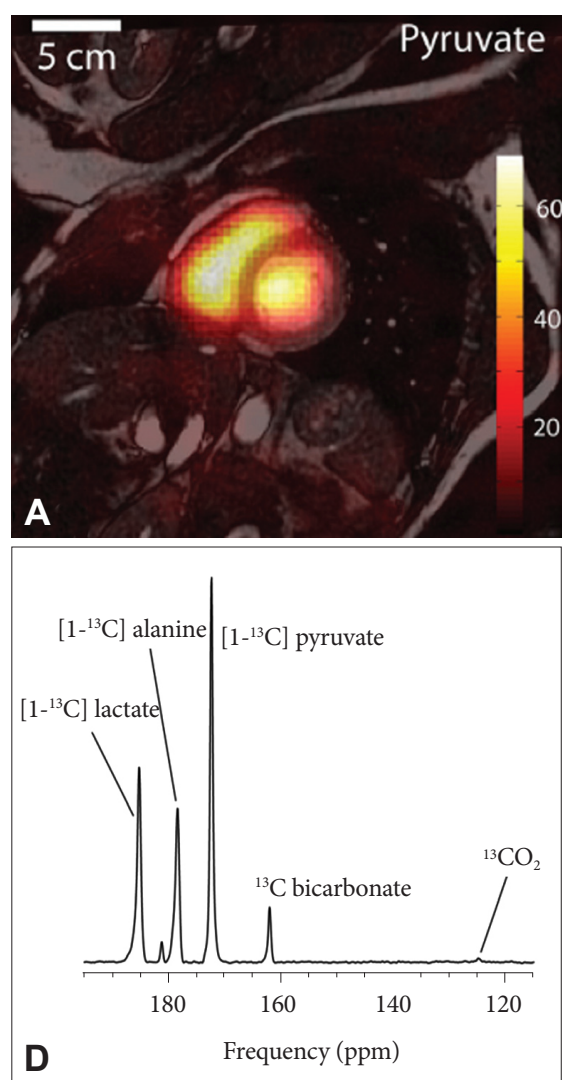

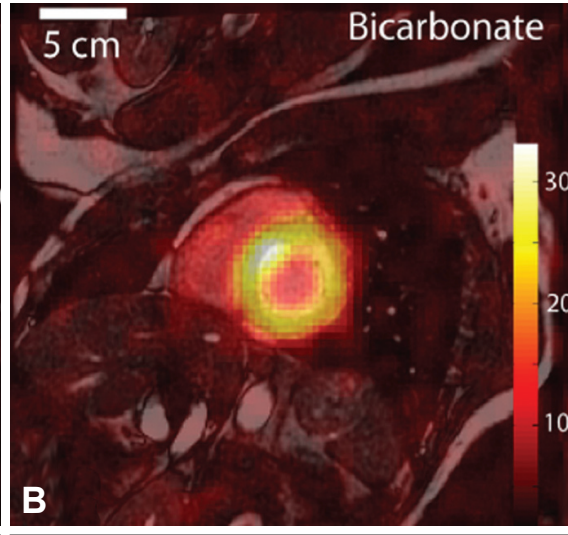

Lactate/pyruvate ratio

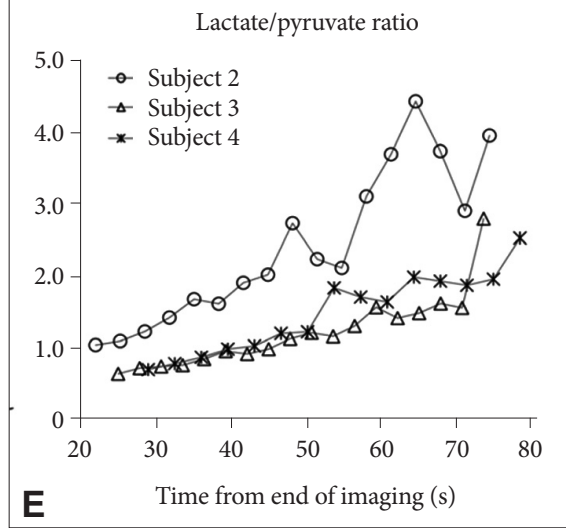

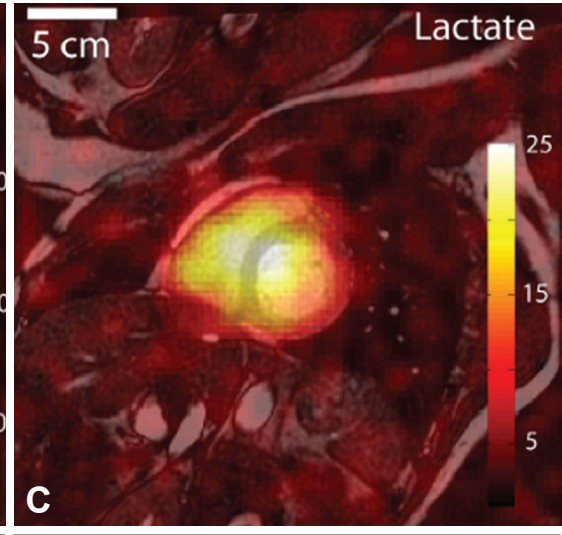

Bicarbonate/pyruvate ratio

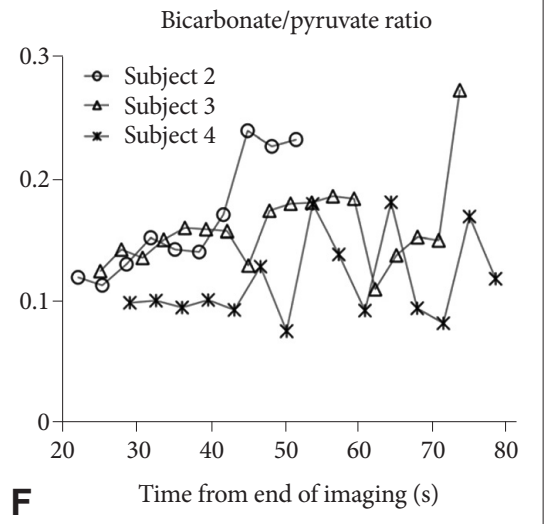

Fig. 9. ${ }^{13} \mathrm{C}$ MR images displayed as color overlays on top of grayscale anatomic images in mid-left ventricle (LV) slices from a healthy subject $(\mathrm{A}-\mathrm{C})$. A representative ${ }^{13} \mathrm{C}$ spectrum acquired using a nonselective excitation pulse is illustrated (D), and the ratios of $\left[1-{ }^{13} \mathrm{C}\right]$ lactate/[1$\left.{ }^{13} \mathrm{C}\right]$ pyruvate and $\left[{ }^{13} \mathrm{C}\right]$ bicarbonate/[1-13 $\left.\mathrm{C}\right]$ pyruvate in three healthy subjects are shown in $(\mathrm{E})$ and $(\mathrm{F})$, respectively. Reprinted from Cunningham et al. Circ Res 2016;119:1177-1182, with permission of Wolters Kluwer Health [21]. 


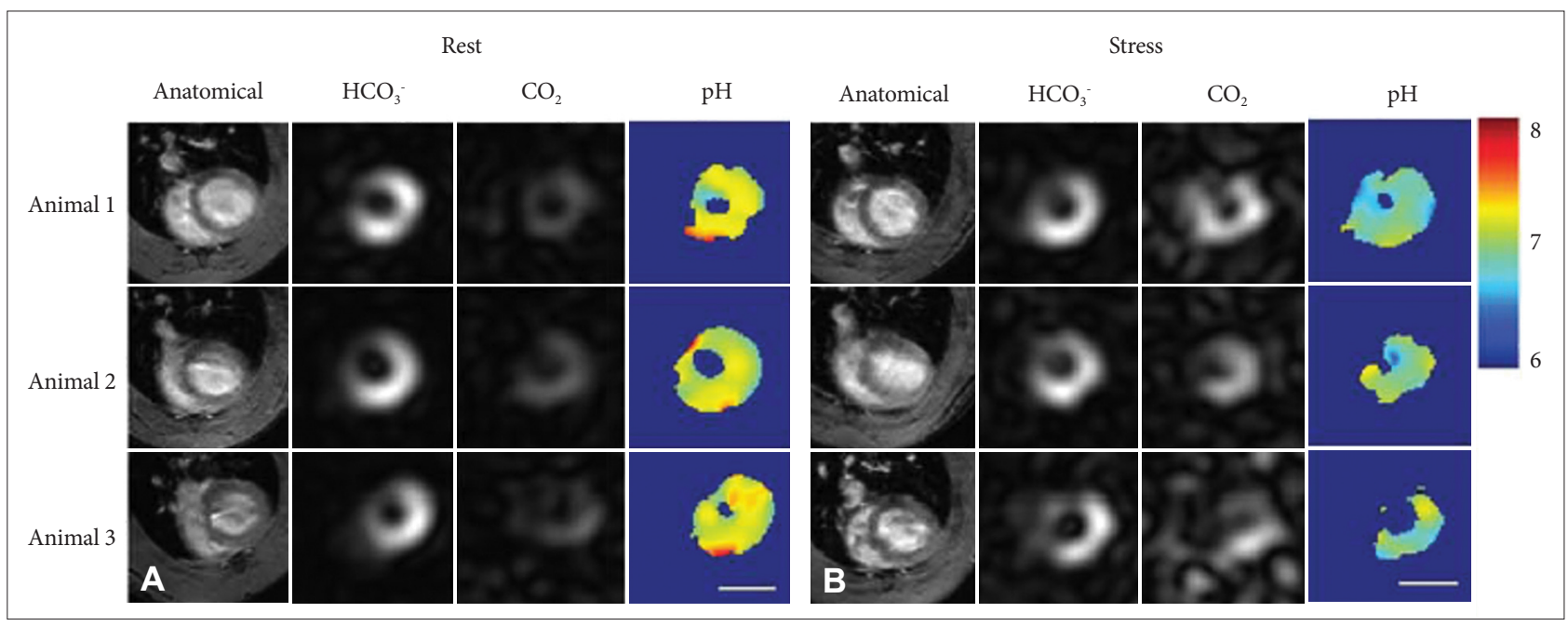

Fig. 10. Intracellular $\mathrm{pH}$ measurements using the ratio between $\mathrm{HCO}_{3}{ }^{-}$and $\mathrm{CO}_{2}$ at equilibrium state on a mid-ventricular slice of rodent heart. The scale bar indicates $1 \mathrm{~cm}$. The $\mathrm{pH}$ level was measured as $7.15 \pm 0.04$ at baseline $(\mathrm{A})$ and decreased to $6.90 \pm 0.06$ following $15 \mathrm{~min}$ of continuous $\beta$-adrenergic stimulation (B). Reprinted from Lau et al. Magn Reson Med 2017;77:1810-1817 [79].

scanner hardware [70].

Several ${ }^{31} \mathrm{P}$ MRS studies [71-73] were performed using a $7 \mathrm{~T}$ MRI unit, which can more precisely quantify the spectral information than a $3 \mathrm{~T}$ unit. It is well known that mean Cramer Rao lower bound indicates spectral fitting uncertainty, and values of PCr and PCr/ATP at $7 \mathrm{~T}$ are 2.4 times and 2.7 times lower than those of $1.5 \mathrm{~T}$, respectively, resulting in enhanced spectral quantification accuracy at a higher field [71]. In a clinical study [74] using $7 \mathrm{~T}$, patients with DCM had a significantly lower $\mathrm{PCr} /$ ATP ratio than healthy controls $(1.54 \pm 0.39$ vs. $1.95 \pm 0.25$, $\mathrm{p}=$ 0.005 ), which is consistent with previous findings at lower field strengths (Fig. 8). A hyperpolarized ${ }^{13} \mathrm{C}$ MRS study [75] at $7 \mathrm{~T}$ enabled assessment of cellular metabolite changes with excellent spatial resolution in the rat heart. A higher field strength such as $7 \mathrm{~T}$ is important to establish a gold standard for quantification of myocardial metabolism by providing accuracy and precision in biochemical quantification.

Recently, a first-in-human study [76] using the DNP hyperpolarization technique was successfully conducted on patients with prostate cancer and suggested the safety and feasibility of hyperpolarized $\left[1-{ }^{13} \mathrm{C}\right]$ pyruvate injections. Cunningham et al. [21] were the first to use hyperpolarized ${ }^{13} \mathrm{C}$ MRS in the human heart, revealing the $\left[{ }^{13} \mathrm{C}\right]$ bicarbonate signal in the LV myocardium and the lactate signal in both the cardiac chambers and the myocardium (Fig. 9). Pyruvic acid has been the most widely used substrate in hyperpolarized ${ }^{13} \mathrm{C}$ studies and was used in the first clinical study. Recently, $\left[1-{ }^{13} \mathrm{C}\right]$ lactic acid and $\left[1-{ }^{13} \mathrm{C}\right]$ butyric acid as samples in DNP have been used to assess cardiac pyruvate dehydrogenase flux and short-chain fatty acid metabolism in animals [77,78]. Further studies in humans with various substrates are needed to obtain additional important information on metabolite-based diagnostic and therapeutic outcomes. In addition, hyperpolarized ${ }^{13} \mathrm{C}$ metabolic imaging has the potential to improve diagnosis and prognosis and to monitor therapeutic response at the cellular level through assessment of heart disease-oriented biochemical pathways, together with cardiac perfusion imaging with hyperpolarized ${ }^{13} \mathrm{C}$ urea and $\mathrm{pH}$ mapping with the Henderson-Hasselbalch equation $\left(\mathrm{pH}=\mathrm{pKa}+\log _{10} \mathrm{HCO}_{3}-/ \mathrm{CO}_{2}\right.$, with $\left.\mathrm{pKa}=6.15\right)$ (Fig. 10) $[36,79]$. Hyperpolarized ${ }^{13} \mathrm{C}$ MRS will be useful for early detection of heart diseases and metabolic mapping of perfusion and intracellular $\mathrm{pH}$.

\section{CONCLUSION}

Cardiac MRS provides fundamental information on changes in myocardial metabolism, especially in ischemic heart disease and heart failure. Although ${ }^{1} \mathrm{H}$ and ${ }^{31} \mathrm{P}$ MRS have limited clinical roles, cardiac MRS is becoming increasingly important in both early detection of and evaluation of the therapeutic response in heart diseases. Together with the use of higher field strength, more accurate outcomes are expected due to enhanced temporal and spatial resolutions. Furthermore, advanced hyperpolarized ${ }^{13} \mathrm{C}$ MRS might lead to development of important diagnostic biomarkers for assessment of various heart diseases by providing additional metabolic information.

\section{Conflicts of Interest}

The authors declare that they have no conflict of interest.

\section{Acknowledgments}

This research was supported by National Research Foundation of Korea grants funded by the Korea government (Ministry of Science and Information and Communication Technology) (2015R1A2A2A01007827, 2018R1A2 B2006260, and 2018R1C1B6005456). 


\section{REFERENCES}

1. Remme WJ. Overview of the relationship between ischemia and congestive heart failure. Clin Cardiol 2000;23(7 Suppl 4):IV4-IV8.

2. Boonprasert P, Lailerd N, Chattipakorn N. Urocortins in heart failure and ischemic heart disease. Int J Cardiol 2008;127:307-312.

3. Benjamin EJ, Blaha MJ, Chiuve SE, Cushman M, Das SR, Deo R, et al. Heart Disease and Stroke Statistics-2017 update: a report from the American Heart Association. Circulation 2017;135:e146-e603.

4. Lopaschuk GD, Folmes CD, Stanley WC. Cardiac energy metabolism in obesity. Circ Res 2007;101:335-347.

5. Lopaschuk GD. Metabolic changes in the acutely ischemic heart. Heart Metab 2016;70:32-35.

6. Doenst T, Nguyen TD, Abel ED. Cardiac metabolism in heart failure: implications beyond ATP production. Circ Res 2013;113:709-724.

7. Bizino MB, Hammer S, Lamb HJ. Metabolic imaging of the human heart: clinical application of magnetic resonance spectroscopy. Heart 2014;100:881-890.

8. Holloway CJ, Suttie J, Dass S, Neubauer S. Clinical cardiac magnetic resonance spectroscopy. Prog Cardiovasc Dis 2011;54:320-327.

9. Task Force Members, Montalescot G, Sechtem U, Achenbach S, Andreotti F, Arden C, Budaj A, et al. 2013 ESC guidelines on the management of stable coronary artery disease: the Task Force on the management of stable coronary artery disease of the European Society of Cardiology. Eur Heart J 2013;34:2949-3003.

10. Ciampi Q, Villari B. Role of echocardiography in diagnosis and risk stratification in heart failure with left ventricular systolic dysfunction. Cardiovasc Ultrasound 2007;5:34.

11. Bottomley PA. Human in vivo NMR spectroscopy in diagnostic medicine: clinical tool or research probe? Radiology 1989;170(1 Pt 1):1-15.

12. Di Costanzo A, Trojsi F, Tosetti M, Giannatempo GM, Nemore F, Piccirillo M, et al. High-field proton MRS of human brain. Eur J Radiol 2003;48:146-153.

13. Bottomley PA, Weiss RG. Non-invasive magnetic-resonance detection of creatine depletion in non-viable infarcted myocardium. Lancet 1998;351: 714-718.

14. Bottomley PA, Weiss RG. Noninvasive localized MR quantification of creatine kinase metabolites in normal and infarcted canine myocardium. Radiology 2001;219:411-418.

15. Buchthal SD, den Hollander JA, Merz CN, Rogers WJ, Pepine CJ, Reichek $\mathrm{N}$, et al. Abnormal myocardial phosphorus-31 nuclear magnetic resonance spectroscopy in women with chest pain but normal coronary angiograms. N Engl J Med 2000;342:829-835.

16. Hudsmith LE, Neubauer S. Magnetic resonance spectroscopy in myocardial disease. JACC Cardiovasc Imaging 2009;2:87-96.

17. Weiss RG, Bottomley PA, Hardy CJ, Gerstenblith G. Regional myocardial metabolism of high-energy phosphates during isometric exercise in patients with coronary artery disease. N Engl J Med 1990;323:1593-1600.

18. Aquaro GD, Frijia F, Positano V, Menichetti L, Santarelli MF, ArdenkjaerLarsen JH, et al. 3D CMR mapping of metabolism by hyperpolarized ${ }^{13} \mathrm{C}-$ pyruvate in ischemia-reperfusion. JACC Cardiovasc Imaging 2013;6:743744 .

19. Golman K, Petersson JS, Magnusson P, Johansson E, Akeson P, Chai CM, et al. Cardiac metabolism measured noninvasively by hyperpolarized ${ }^{13} \mathrm{C}$ MRI. Magn Reson Med 2008;59:1005-1013.

20. Schroeder MA, Atherton HJ, Ball DR, Cole MA, Heather LC, Griffin JL, et al. Real-time assessment of Krebs cycle metabolism using hyperpolarized ${ }^{13} \mathrm{C}$ magnetic resonance spectroscopy. FASEB J 2009;23:2529-2538.

21. Cunningham CH, Lau JY, Chen AP, Geraghty BJ, Perks WJ, Roifman I, et al. Hyperpolarized ${ }^{13} \mathrm{C}$ metabolic MRI of the human heart: initial experience. Circ Res 2016;119:1177-1182.

22. Mariotti E, Orton MR, Eerbeek O, Ashruf JF, Zuurbier CJ, Southworth R, et al. Modeling non-linear kinetics of hyperpolarized $\left[1-{ }^{13} \mathrm{C}\right]$ pyruvate in the crystalloid-perfused rat heart. NMR Biomed 2016;29:377-386.

23. Kim TH, Jeong GW, Kim TS, Kim YH. Myocardial metabolic abnormali- ty in a primary left atrial rhabdomyosarcoma: localized ${ }^{1} \mathrm{H}$ MR spectroscopy. Iran J Radiol 2015;12:e17757.

24. Friedrich J, Apstein CS, Ingwall JS. ${ }^{31} \mathrm{P}$ nuclear magnetic resonance spectroscopic imaging of regions of remodeled myocardium in the infarcted rat heart. Circulation 1995;92:3527-3538.

25. Kim HK, Kim TH, Kim GW, Kim JB, Jeong GW. Growth-related changes of phosphorus metabolites in VX-2 carcinoma implanted into rabbit thigh muscle: in vivo ${ }^{31} \mathrm{P}$ MR spectroscopy. Indian J Anim Res 2017;51:121-128.

26. Shivu GN, Abozguia K, Phan TT, Ahmed I, Henning A, Frenneaux M. (31)P magnetic resonance spectroscopy to measure in vivo cardiac energetics in normal myocardium and hypertrophic cardiomyopathy: Experiences at 3T. Eur J Radiol 2010;73:255-259.

27. Beer M, Seyfarth T, Sandstede J, Landschütz W, Lipke C, Köstler H, et al. Absolute concentrations of high-energy phosphate metabolites in normal, hypertrophied, and failing human myocardium measured noninvasively with ${ }^{31} \mathrm{P}-\mathrm{SLOOP}$ magnetic resonance spectroscopy. J Am Coll Cardiol 2002; 40:1267-1274.

28. Neubauer S, Horn M, Cramer M, Harre K, Newell JB, Peters W, et al. Myocardial phosphocreatine-to-ATP ratio is a predictor of mortality in patients with dilated cardiomyopathy. Circulation 1997;96:2190-2196.

29. Kim GW, Oh CH, Kim JC, Yoon W, Jeong YY, Kim YH, et al. Noninvasive biomarkers for acute hepatotoxicity induced by 1,3-dichloro-2-propanol: hyperpolarized ${ }^{13} \mathrm{C}$ dynamic MR spectroscopy. Magn Reson Imaging 2016;34:159-165.

30. Ardenkjaer-Larsen JH, Fridlund B, Gram A, Hansson G, Hansson L, Lerche $\mathrm{MH}$, et al. Increase in signal-to-noise ratio of $>10000$ times in liquid-state NMR. Proc Natl Acad Sci U S A 2003;100:10158-10163.

31. Chen AP, Albers MJ, Cunningham CH, Kohler SJ, Yen YF, Hurd RE, et al. Hyperpolarized C-13 spectroscopic imaging of the TRAMP mouse at 3T-initial experience. Magn Reson Med 2007;58:1099-1106.

32. Moon CM, Oh CH, Ahn KY, Yang JS, Kim JY, Shin SS, et al. Metabolic biomarkers for non-alcoholic fatty liver disease induced by high-fat diet: in vivo magnetic resonance spectroscopy of hyperpolarized $\left[1-{ }^{13} \mathrm{C}\right] \mathrm{py}-$ ruvate. Biochem Biophys Res Commun 2017;482:112-119.

33. Kim GW, Ahn KY, Kim YH, Jeong GW. Time-course metabolic changes in high-fat diet-induced obesity rats: a pilot study using hyperpolarized (13)C dynamic MRS. Magn Reson Imaging 2016;34:1199-1205.

34. Albers MJ, Bok R, Chen AP, Cunningham CH, Zierhut ML, Zhang VY, et al. Hyperpolarized ${ }^{13} \mathrm{C}$ lactate, pyruvate, and alanine: noninvasive biomarkers for prostate cancer detection and grading. Cancer Res 2008;68: 8607-8615.

35. Faller KM, Lygate CA, Neubauer S, Schneider JE. ${ }^{1} \mathrm{H}-\mathrm{MR}$ spectroscopy for analysis of cardiac lipid and creatine metabolism. Heart Fail Rev 2013;18:657-668.

36. Lau AZ, Miller JJ, Robson MD, Tyler DJ. Cardiac perfusion imaging using hyperpolarized (13)C urea using flow sensitizing gradients. Magn Reson Med 2016;75:1474-1483.

37. Johnson BD, Shaw LJ, Buchthal SD, Bairey Merz CN, Kim HW, Scott KN, et al. Prognosis in women with myocardial ischemia in the absence of obstructive coronary disease: results from the National Institutes of HealthNational Heart, Lung, and Blood Institute-Sponsored Women's Ischemia Syndrome Evaluation (WISE). Circulation 2004;109:2993-2999.

38. Beer M, Viehrig M, Seyfarth T, Sandstede J, Lipke C, Pabst T, et al. [Cardiac energy metabolism in heart valve diseases with ${ }^{31} \mathrm{P} \mathrm{MR}$ spectroscopy]. Radiologe 2000;40:162-167.

39. Yabe T, Mitsunami K, Inubushi T, Kinoshita M. Quantitative measurements of cardiac phosphorus metabolites in coronary artery disease by ${ }^{31} \mathrm{P}$ magnetic resonance spectroscopy. Circulation 1995;92:15-23.

40. Schroeder MA, Swietach P, Atherton HJ, Gallagher FA, Lee P, Radda GK, et al. Measuring intracellular $\mathrm{pH}$ in the heart using hyperpolarized carbon dioxide and bicarbonate: $\mathrm{a}^{13} \mathrm{C}$ and ${ }^{31} \mathrm{P}$ magnetic resonance spectroscopy study. Cardiovasc Res 2010;86:82-91.

41. von Kienlin M, Rösch C, Le Fur Y, Behr W, Roder F, Haase A, et al. Three-dimensional ${ }^{31} \mathrm{P}$ magnetic resonance spectroscopic imaging of regional high-energy phosphate metabolism in injured rat heart. Magn 
Reson Med 1998;39:731-741.

42. Nakae I, Mitsunami K, Yabe T, Inubushi T, Morikawa S, Matsuo S, et al. Detection of metabolic abnormality in asynergic regions of ischemic human myocardium using ${ }^{31} \mathrm{P}$ and ${ }^{1} \mathrm{H}$ magnetic resonance spectroscopy. J Cardiovasc Magn Reson 2004;6:685-696.

43. Bouchard A, Doyle M, Wolkowicz PE, Wilson R, Evanochko WT, Pohost GM. Visualization of altered myocardial lipids by ${ }^{1} \mathrm{H}$ NMR chemical-shift imaging following ischemic insult. Magn Reson Med 1991;17:379-389.

44. Evanochko WT, Reeves RC, Sakai TT, Canby RC, Pohost GM. Proton NMR spectroscopy in myocardial ischemic insult. Magn Reson Med 1987; 5:23-31.

45. Barba I, Jaimez-Auguets E, Rodriguez-Sinovas A, Garcia-Dorado D. ${ }^{1} \mathrm{H}$ NMR-based metabolomic identification of at-risk areas after myocardial infarction in swine. MAGMA 2007;20:265-271.

46. Horn M, Weidensteiner C, Scheffer H, Meininger M, de Groot M, Remkes $\mathrm{H}$, et al. Detection of myocardial viability based on measurement of sodium content: a ${ }^{23} \mathrm{Na}-\mathrm{NMR}$ study. Magn Reson Med 2001;45:756764.

47. Oh-Ici D, Wespi P, Busch J, Wissmann L, Krajewski M, Weiss K, et al. Hyperpolarized metabolic MR imaging of acute myocardial changes and recovery after ischemia-reperfusion in a small-animal model. Radiology 2016;278:742-751.

48. Shiojima I, Komuro I. [Molecular mechanisms of congestive heart failure]. Nihon Rinsho 2006;64:826-831.

49. Richard P, Villard E, Charron P, Isnard R. The genetic bases of cardiomyopathies. J Am Coll Cardiol 2006;48:A79-A89.

50. Neubauer S. The failing heart--an engine out of fuel. N Engl J Med 2007; 356:1140-1051.

51. Nakae I, Mitsunami K, Yoshino T, Omura T, Tsutamoto T, Matsumoto T, et al. Clinical features of myocardial triglyceride in different types of cardiomyopathy assessed by proton magnetic resonance spectroscopy: comparison with myocardial creatine. J Card Fail 2010;16:812-822.

52. Fragasso G, Perseghin G, De Cobelli F, Esposito A, Palloshi A, Lattuada $\mathrm{G}$, et al. Effects of metabolic modulation by trimetazidine on left ventricular function and phosphocreatine/adenosine triphosphate ratio in patients with heart failure. Eur Heart J 2006;27:942-948.

53. Neubauer S, Krahe T, Schindler R, Horn M, Hillenbrand H, Entzeroth C, et al. ${ }^{31} \mathrm{P}$ magnetic resonance spectroscopy in dilated cardiomyopathy and coronary artery disease. Altered cardiac high-energy phosphate metabolism in heart failure. Circulation 1992;86:1810-1818.

54. Neubauer S, Horn M, Pabst T, Gödde M, Lübke D, Jilling B, et al. Contributions of 31P-magnetic resonance spectroscopy to the understanding of dilated heart muscle disease. Eur Heart J 1995;16 Suppl O:115-118.

55. de Roos A, Doornbos J, Luyten PR, Oosterwaal LJ, van der Wall EE, den Hollander JA. Cardiac metabolism in patients with dilated and hypertrophic cardiomyopathy: assessment with proton-decoupled P-31 MR spectroscopy. J Magn Reson Imaging 1992;2:711-719.

56. Ternovoy SK, Mazaev VV, Stukalova OV, Serova NS. $\left[{ }^{31} \mathrm{P}\right.$ magnetic resonance spectroscopy in patients with various genesis of left ventricular hypertrophy]. Kardiologiia 2015;55:5-9.

57. Crilley JG, Boehm EA, Blair E, Rajagopalan B, Blamire AM, Styles P, et al. Hypertrophic cardiomyopathy due to sarcomeric gene mutations is characterized by impaired energy metabolism irrespective of the degree of hypertrophy. J Am Coll Cardiol 2003;41:1776-1182.

58. Secchi F, Di Leo G, Petrini M, Spairani R, Alì M, Guazzi M, et al. ${ }^{1} \mathrm{H}$ - and ${ }^{31} \mathrm{P}$-myocardial magnetic resonance spectroscopy in non-obstructive hypertrophic cardiomyopathy patients and competitive athletes. Radiol Med 2017;122:265-272.

59. Stanley WC. Changes in cardiac metabolism: a critical step from stable angina to ischaemic cardiomyopathy. Eur Heart J Supplements 2001;3:O2O7.

60. Scheuermann-Freestone M, Madsen PL, Manners D, Blamire AM, Buckingham RE, Styles $\mathrm{P}$, et al. Abnormal cardiac and skeletal muscle energy metabolism in patients with type 2 diabetes. Circulation 2003;107:3040-
3046.

61. Metzler B, Schocke MF, Steinboeck P, Wolf C, Judmaier W, Lechleitner $\mathrm{M}$, et al. Decreased high-energy phosphate ratios in the myocardium of men with diabetes mellitus type I. J Cardiovasc Magn Reson 2002;4:493502.

62. Nakae I, Mitsunami K, Matsuo S, Matsumoto T, Morikawa S, Inubushi T, et al. Assessment of myocardial creatine concentration in dysfunctional human heart by proton magnetic resonance spectroscopy. Magn Reson Med Sci 2004;3:19-25.

63. Nakae I, Mitsunami K, Omura T, Yabe T, Tsutamoto T, Matsuo S, et al. Proton magnetic resonance spectroscopy can detect creatine depletion associated with the progression of heart failure in cardiomyopathy. J Am Coll Cardiol 2003;42:1587-1593

64. Du Z, Shen A, Huang Y, Su L, Lai W, Wang P, et al. 'H-NMR-based metabolic analysis of human serum reveals novel markers of myocardial energy expenditure in heart failure patients. PLoS One 2014;9:e88102.

65. Rijzewijk LJ, van der Meer RW, Smit JW, Diamant M, Bax JJ, Hammer S, et al. Myocardial steatosis is an independent predictor of diastolic dysfunction in type 2 diabetes mellitus. J Am Coll Cardiol 2008;52:1793-1799.

66. Szczepaniak LS, Dobbins RL, Metzger GJ, Sartoni-D'Ambrosia G, Arbique D, Vongpatanasin W, et al. Myocardial triglycerides and systolic function in humans: in vivo evaluation by localized proton spectroscopy and cardiac imaging. Magn Reson Med 2003;49:417-423.

67. Schroeder MA, Lau AZ, Chen AP, Gu Y, Nagendran J, Barry J, et al. Hyperpolarized (13)C magnetic resonance reveals early- and late-onset changes to in vivo pyruvate metabolism in the failing heart. Eur J Heart Fail 2013;15:130-140.

68. Seymour AM, Giles L, Ball V, Miller JJ, Clarke K, Carr CA, et al. In vivo assessment of cardiac metabolism and function in the abdominal aortic banding model of compensated cardiac hypertrophy. Cardiovasc Res 2015;106:249-260.

69. Tyler DJ, Hudsmith LE, Clarke K, Neubauer S, Robson MD. A comparison of cardiac (31)P MRS at 1.5 and 3 T. NMR Biomed 2008;21:793-798.

70. Pradhan S, Bonekamp S, Gillen JS, Rowland LM, Wijtenburg SA, Edden RA, et al. Comparison of single voxel brain MRS AT 3T and 7T using 32-channel head coils. Magn Reson Imaging 2015;33:1013-1018.

71. Rodgers CT, Clarke WT, Snyder C, Vaughan JT, Neubauer S, Robson MD. Human cardiac 31P magnetic resonance spectroscopy at 7 Tesla. Magn Reson Med 2014;72:304-315.

72. Schaller B, Clarke WT, Neubauer S, Robson MD, Rodgers CT. Suppression of skeletal muscle signal using a crusher coil: A human cardiac ${ }^{31} \mathrm{P}$ MR spectroscopy study at 7 tesla. Magn Reson Med 2016;75:962-972.

73. Valkovič L, Clarke WT, Purvis LAB, Schaller B, Robson MD, Rodgers CT. Adiabatic excitation for ${ }^{31} \mathrm{P} M R$ spectroscopy in the human heart at 7 T: A feasibility study. Magn Reson Med 2017;78:1667-1673.

74. Stoll VM, Clarke WT, Levelt E, Liu A, Myerson SG, Robson MD, et al. Dilated cardiomyopathy: phosphorus ${ }^{31} \mathrm{MR}$ spectroscopy at $7 \mathrm{~T}$. Radiology 2016;281:409-417.

75. Miller JJ, Lau AZ, Teh I, Schneider JE, Kinchesh P, Smart S, et al. Robust and high resolution hyperpolarized metabolic imaging of the rat heart at 7 T with 3D spectral-spatial EPI. Magn Reson Med 2016;75:1515-1524.

76. Nelson SJ, Kurhanewicz J, Vigneron DB, Larson PE, Harzstark AL, Ferrone $\mathrm{M}$, et al. Metabolic imaging of patients with prostate cancer using hyperpolarized $\left[1-{ }^{13} \mathrm{C}\right]$ pyruvate. Sci Transl Med 2013;5:198ra108.

77. Chen AP, Lau JY, Alvares RD, Cunningham CH. Using $\left[1-{ }^{13} \mathrm{C}\right]$ lactic acid for hyperpolarized ${ }^{13} \mathrm{C}$ MR cardiac studies. Magn Reson Med 2015;73: 2087-2093.

78. Ball DR, Rowlands B, Dodd MS, Le Page L, Ball V, Carr CA, et al. Hyperpolarized butyrate: a metabolic probe of short chain fatty acid metabolism in the heart. Magn Reson Med 2014;71:1663-1669.

79. Lau AZ, Miller JJ, Tyler DJ. Mapping of intracellular $\mathrm{pH}$ in the in vivo rodent heart using hyperpolarized $\left[1-{ }^{13} \mathrm{C}\right]$ pyruvate. Magn Reson Med 2017; 77:1810-1817. 